\title{
Circuit
}

Musiques contemporaines

\section{Un pays à faire : allocution à l'occasion de la remise des prix du Québec 1991}

\section{Gilles Tremblay}

Volume 5, numéro 1, 1994

Gilles Tremblay : réflexions

URI : https://id.erudit.org/iderudit/902093ar

DOI : https://doi.org/10.7202/902093ar

Aller au sommaire du numéro

Éditeur(s)

Les Presses de l'Université de Montréal

ISSN

1183-1693 (imprimé)

1488-9692 (numérique)

Découvrir la revue

Citer ce document

Tremblay, G. (1994). Un pays à faire : allocution à l'occasion de la remise des prix du Québec 1991. Circuit, 5(1), 61-62. https://doi.org/10.7202/902093ar d'utilisation que vous pouvez consulter en ligne.

https://apropos.erudit.org/fr/usagers/politique-dutilisation/ 


\section{Allocution à l'occasion de la remise des prix du Québec 1991}

I Prononcé le 28 octobre 1991. Archives du compositeur.

Recevoir le Prix du Québec me touche profondément. J'en remercie le gouvernement du Québec ainsi que les membres du jury. Je vois dans ce geste, au risque d'une certaine naïveté, une sorte de tendresse collective, et profite de l'occasion pour rendre hommage à tous ceux qui m'ont soutenu et aidé : mes parents (ma mère est parmi nous), ma famille, mon épouse Jacqueline et mes enfants Joëlle, Jean-François, Emmanuel et Guillaume; mes professeurs, élèves, amis et interprètes, mes collègues du Conservatoire de musique du Québec, institution fondée par Wilfrid Pelletier; ainsi qu'au rôle de madame Maryvonne Kendergi dans son dévouement à la musique contemporaine. C'est à un compositeur qu'échoit cette année le Prix Denise-Pelletier pour les arts d'interprétation et ce choix a valeur de symbole puisque la composition est antérieure à l'interprétation: il est témoignage envers l'exploration, l'invention, la découverte; envers une démarche faite de risque, de gratuité, de succès nonassuré, souvent à contre-courant, mais chargée d'une nécessité impérieuse. Cette démarche, faite à la fois d'intuition et de science, est partagée avec tous ceux qui cherchent: savants, artistes, poètes, et avec tout ce qu'il y a de savants, d'artistes et de poètes en chacun de nous - d'où l'aspect collectif du geste individuel - dans une perspective globale de communion, amorcée par l'émerveillement, l'étonnement premier: à l'instar de l'enfant. Puisqu'il y a symbole, je le partage avec tous mes collèges et amis compositeurs, des aînés aux plus jeunes dont la situation est non seulement difficile mais précaire. (Ne serionsnous pas devenus des bélugas culturels ?...). Considérant ce symbole comme un signe prometteur, j'invite du même souffle le gouvernement du Québec à combler un vide inexplicable en matière d'aide à la composition musicale sous forme, entre autres, de commandes d'œuvres. À ce moment historique où de nouvelles responsabilités s'offrent à l'avenir du Québec et quelles qu'en soient les voies, je me permets de souligner l'urgence d'une véritable priorité à la culture, non pas comme supplément ornemental, mais partie intégrante et essentielle de la vie. L'économie prendrait ainsi un sens élargi et renouvelé où l'esprit, le non-quantifiable, le non-mesurable, et le qualitatif engendrerait non seulement un espace, mais un espace respirable, pierre de touche d'une société vivante et féconde. Voilà, avec ma reconnaissance, tout le sens attaché à ce prix. 


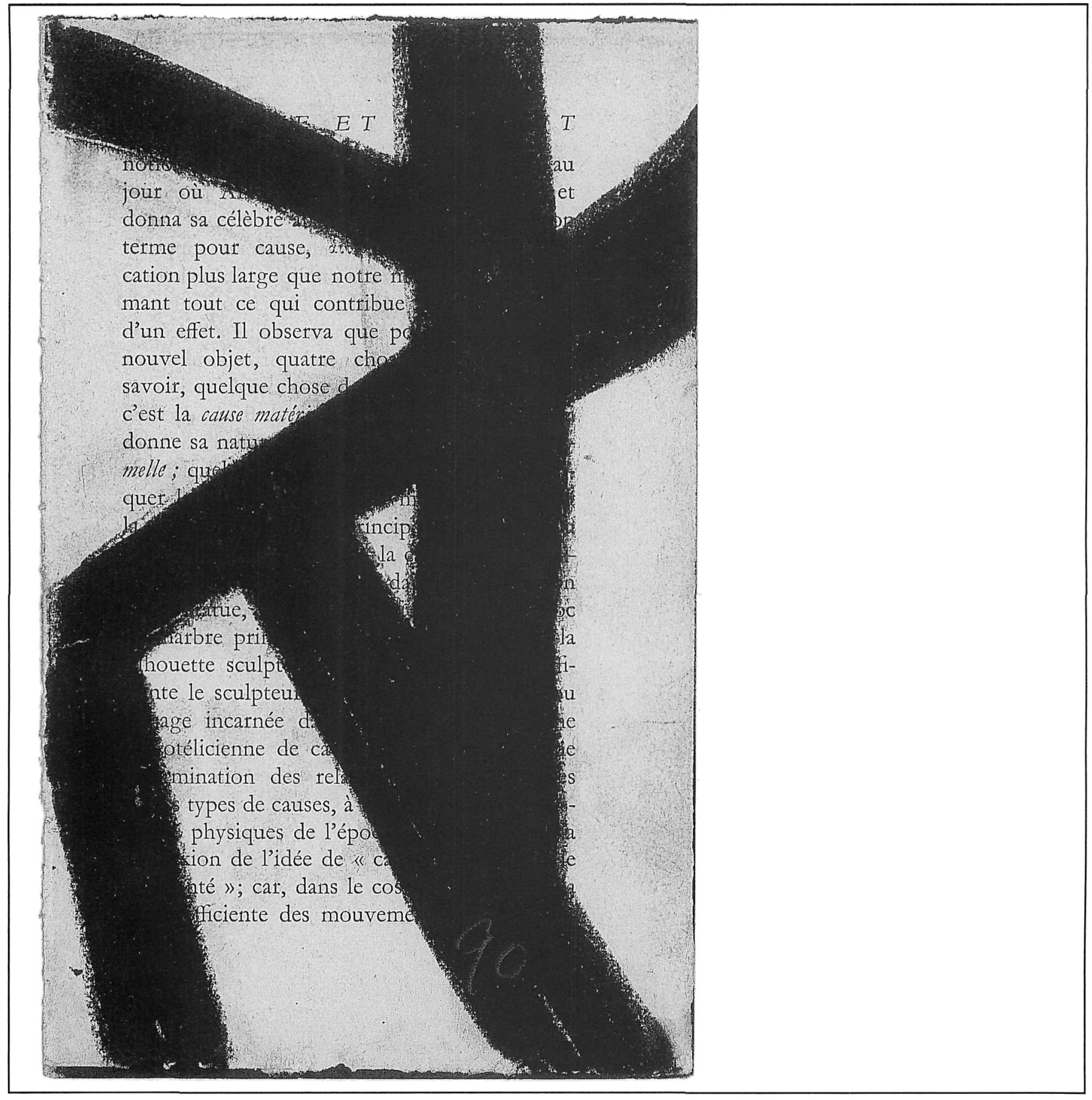

